\title{
A RARE CASE OF PURE WHITE CELL APLASIA IN A PATIENT WITH THYMOMA COMPLICATED BY INFECTIVE ENDOCARDITIS
}

\author{
Leonid I. DVORETSKY ${ }^{1}$, Sergei V. YAKOVLEV ${ }^{1}$, Margarita P. SUVOROVA ${ }^{1}$, \\ Valeriy V. VARYASIN ${ }^{2}$, Andrey P. STEPANCHENKO ${ }^{3}$, Maria A. KARNAUSHKINA ${ }^{4 凶}$
}

${ }^{1}$ I.M. Sechenov First Moscow State Medical University (Sechenov University), Moscow, Russian Federation

${ }^{2}$ Municipal Hospital \#52 of the Moscow Healthcare Department, Moscow, Russian Federation

${ }^{3}$ Municipal Hospital named after S.S. Yudin of the Moscow Healthcare Department, Moscow, Russian Federation

${ }^{4}$ Federal State Autonomous Educational Institution of Higher Education "Peoples' Friendship University of Russia” (RUDN University), Russian Federation

\section{Abstract}

Introduction. Pure white cell aplasia (PWCA) is a rare hematologic disorder characterized by the absence of neutrophil lineages in the bone marrow, with intact megakaryopoiesis and erythropoiesis. PWCA is commonly associated with several immune pathologies. Cytopenia in patients with thymoma is a paraneoplastic syndrome, along with other manifestations. The two major clinical issues in PWCA are various infectious complications and ulcerative-necrotic lesions of the skin and mucosa membranes.

Case presentation. We present a rare case of a patient with thymoma and PWCA, as paraneoplastic syndrome. On the background of agranulocytosis, the patient developed sepsis and infective endocarditis (IE) caused by a rare agent, carbapenem-resistant Klebsiella pneumoniae.

Conclusions. The rarity of endocarditis caused by Klebsiella species limits its recognition and awareness

\section{Résumé}

Un cas rare d'aplasie pure des globules blancs chez un patient avec un thymome compliqué d'une endocardite infectieuse

Introduction. Laplasie pure des globules blancs (PWCA) est une maladie hématologique rare caractérisée par l'absence de lignées de neutrophiles dans la moelle osseuse avec mégacaryopoièse et érythropoï̀se intactes. La PWCA est généralement associée à plusieurs pathologies immunitaires. La cytopénie chez les patients atteints de thymome est considérée comme l'une des maladies des syndromes paranéoplasiques avec d'autres manifestations. Les deux principaux problèmes cliniques de la PWCA sont diverses complications infectieuses et les lésions ulcéreuses-nécrotiques de la peau et des muqueuses.

Rapport de cas. Cet article décrit le cas rare d'un patient atteint de thymome et de l'un de ses syndromes 
of its often severe course. Most cases of endocarditis with Klebsiella pneumoniae are associated with prosthetic heart valves. In patients with immunosuppression, such as PWCA associated with thymoma, and endocarditis, rare microorganisms must be considered.

Keywords: pure white cell aplasia, thymoma, infective endocarditis, neutropenia, agranulocytosis.

\section{List of abbreviations:}

AG - agranulocytosis

CT - computed tomography

CRP - C-reactive protein

ESBL - extended spectrum beta-lactamases

IE - infective endocarditis

PWCA - pure white cell aplasia

PNS - paraneoplastic syndromes

\section{INTRODUCTION}

Pure white cell aplasia (PWCA) is a rare hematologic disorder characterized by the absence of neutrophil lineages in the bone marrow, with intact megakaryopoiesis and erythropoiesis ${ }^{1}$.

The main pathogenetic mechanism of PWCA is considered to be the immune-mediated suppression of granulopoiesis, with autoantibodies against the progenitor cells of granulocytes ${ }^{1}$ and subsequent inhibition of granulocyte-macrophage colony-forming units $^{2}$. PWCA is commonly associated with several immune diseases (autoimmune hepatitis and primary biliary cirrhosis ${ }^{3,4}$, autoimmune thyroiditis with autoantibodies to striated muscle cells and $\mathrm{CD} 8^{+}$naive paranéoplasiques - une aplasie pure des globules blancs. Sur fond d'agranulocytose, il a développé une septicémie et une endocardite infectieuse, causée par un agent rare - Klebsiella pneumoniae résistant aux carbapénèmes.

Conclusions. La rareté de l'endocardite causée par l'espèce Klebsiella limite sa reconnaissance et la prise de conscience de son évolution souvent sévère. La plupart des cas d'endocardite à Klebsiella pneumoniae sont associés à des valves cardiaques prothétiques. Chez les patients présentant une immunosuppression, telle qu'une PWCA associée à un thymome et une endocardite, des micro-organismes rares doivent être pris en compte.

Mots-clés: aplasie pure des globules blancs, thymome, endocardite infectieuse, neutropénie, agranulocytose.

cells $\left.{ }^{5}\right)$. There have been described cases of recurrent PWCA after bone marrow transplantation, successfully treated with biological drugs ${ }^{6-9}$. Also, some of the reports described as "cases of agranulocytosis in patients with thymoma" may also be considered a manifestation of PWCA. This hypothesis may be confirmed by bone marrow histology (a pronounced decrease in the number of neutrophilic granulocytes), normal erythrocyte and platelet counts, and the history of treatment with immunosuppressive drugs (immunosuppressants, immunoglobulin drugs, cytostatics, genetically-engineered drugs $)^{10,11}$.

Cytopenia in patients with thymoma is considered a paraneoplastic syndrome $e^{12}$, along with other manifestations ${ }^{13}$. The primary cause of paraneoplastic
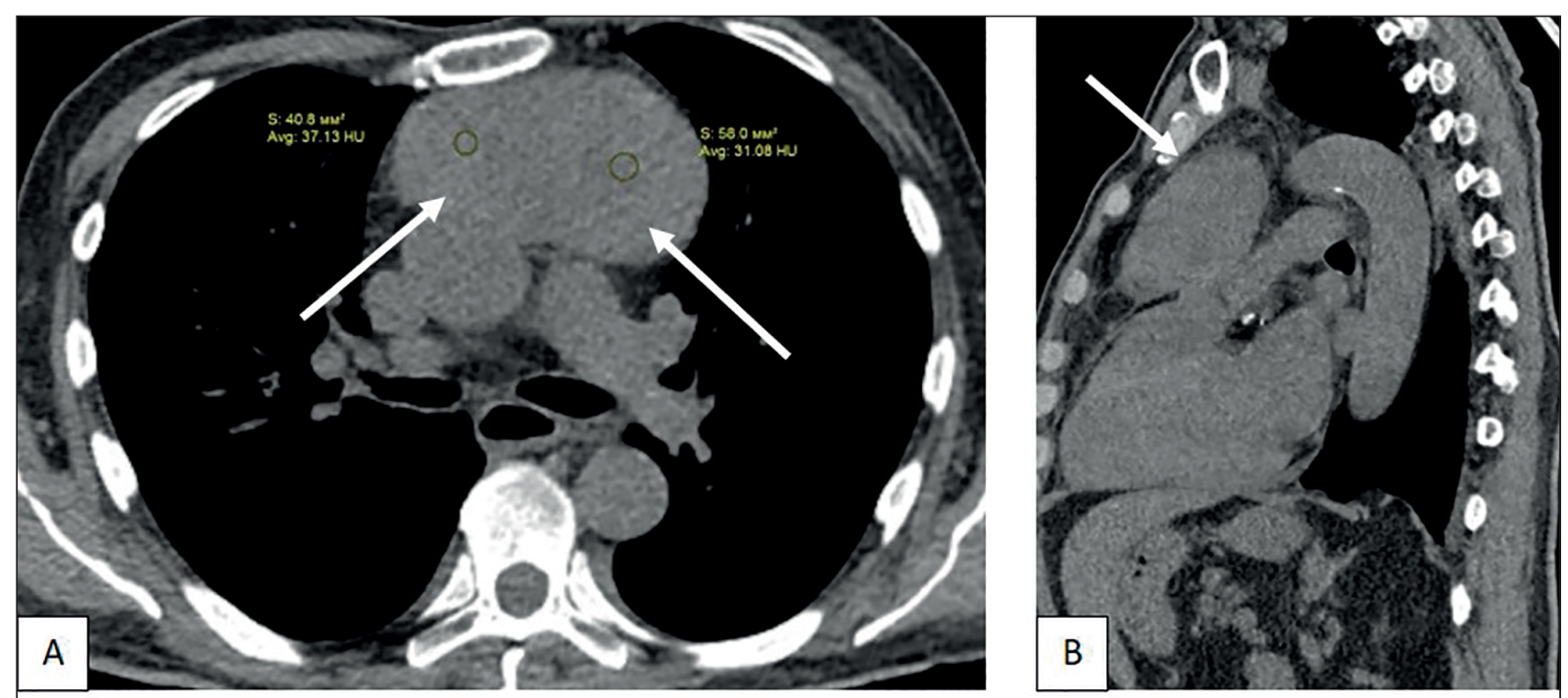

Figure 1. Chest CT, soft tissue window (A,B). Large anterior mediastinal mass (arrows), 102x60x51 mm, with smooth contours, adjacent to the aorta and pulmonary trunk. Although it has a heterogeneous structure on the native $\mathrm{CT}$, it demonstrated regular contrast enhancement. 
syndromes in thymoma is dysregulation of thymus activity. Thymic epithelial cells have a lower expression profile of autoimmune regulator and major histocompatibility complex, and thymic architectonics becomes disrupted, leading to autoimmune complications ${ }^{14}$. Other causes of PWCA include viral infections, particularly parvovirus B19 infection ${ }^{15}$, and drugs $^{16-18}$.

The two major clinical issues in PWCA are various infectious complications and ulcerative-necrotic lesions of the skin and mucosa membranes. It is essential to identify the correct cause of these complications and provide adequate therapy for both clinical manifestations and underlying neutropenia.

\section{Case presentation}

A 68-year-old man was admitted to the hospital for fever, exertion dyspnea, and skin ulcers on the terminal phalanges of the $2^{\text {nd }}$ and $3^{\text {rd }}$ fingers of
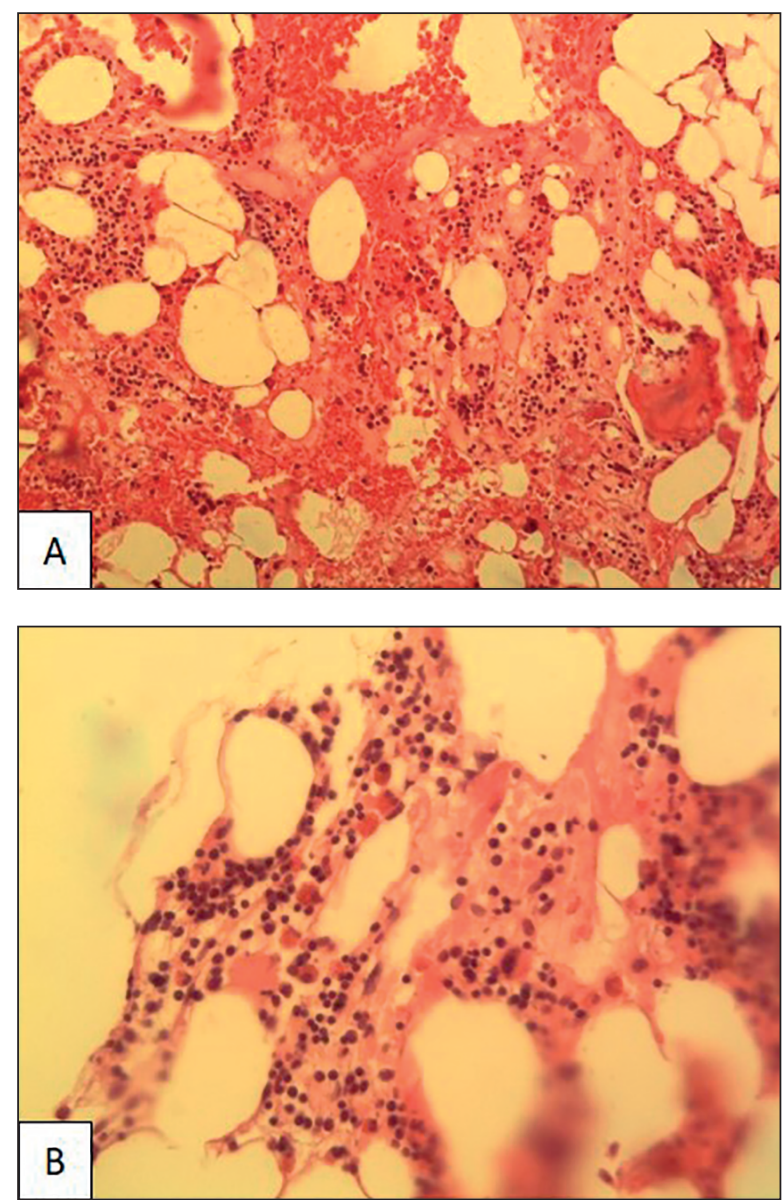

Figure 2. Tissue section of bone marrow.

Fatty bone marrow prevails over the active. Erythropoiesis is represented by young forms. Granulocytopoiesis is markedly reduced, mature forms predominate. There are also single eosinophilic cells and megakaryocytes.

A. H\&E staining, x200. B. H\&E staining, x400. both hands. He was hospitalized for the first time nine months before, with a presumptive diagnosis of pneumonia. On that time, an anterior mediastinal mass (Fig. 1) and pronounced neutropenia (up to 400 cells/L) were revealed.

The biopsy of the mass demonstrated a thymoma, type AB. The sternal puncture and trepanobiopsy did not confirm the assumption of a lymphoproliferative disease with bone marrow damage (Fig. 2).

As preoperative preparation, a recombinant human granulocyte colony-stimulating factor was prescribed, which successfully increased the number of neutrophils in the peripheral blood.

The patient was hospitalized in our hospital in a severe clinical state. Although there were no significant findings during the clinical examination, except for skin changes and basal crackles in both lungs, the blood tests demonstrated severe leukopenia (leukocytes $1.01 \times 10^{9} / \mathrm{L}$ ) and neutropenia (neutrophils $4 \%$, lymphocytes $76 \%$, eosinophils $3 \%$, monocytes

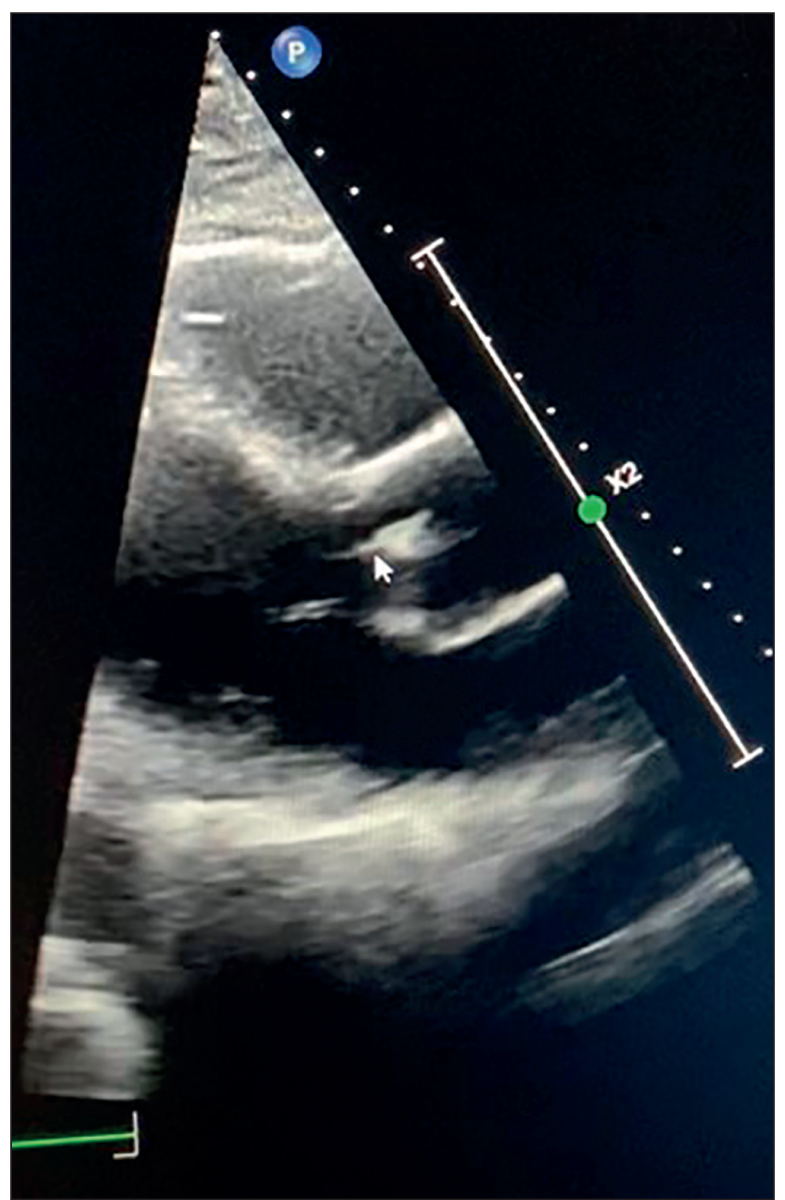

Figure 3. Echocardiography vegetations on the aortic valve. 
$17 \%$ ), mild anemia (hemoglobin $10.9 \mathrm{~g} / \mathrm{dL}$, erythrocytes $\left.4.04 \times 10^{12} / \mathrm{L}\right)$, hyperglycemia $(6.8 \mathrm{mmol} / \mathrm{L})$, elevated total bilirubin $(45.8 \mathrm{mmol} / \mathrm{L})$ and lactate dehydrogenase (100 IU/L), and significantly increased C-reactive protein $(270 \mathrm{mg} / \mathrm{L})$.

The skin changes presented as painful black ulcers covered by scab, surrounded by hyperemia on the terminal phalanges of the thumbs, and pustular elements on the neck and forehead.

Chest computed tomography revealed infiltrative changes in basal lung segments, bilaterally, interpreted as bacterial pneumonia.

The microbiological examination of the secretion of pustulas and ulcers revealed contamination with Staphylococcus aureus, $10^{5} \mathrm{CFU} / \mathrm{mL}$, sensitive to cefoxitin and oxacillin.

The microbiological examination of the sputum was performed twice. Upon admission, Escherichia coli was detected, $10^{6} \mathrm{CFU} / \mathrm{mL}$, produced ESBL, sensitive to carbapenems, beta-lactams and tigecycline. On the $10^{\text {th }}$ day of hospitalization, the examination revealed Acinetobacter baumannii $10^{6} \mathrm{CFU} / \mathrm{mL}$, sensitive only to polymyxin and tigecycline. The hemocultures, performed at the same time (on the $10^{\text {th }}$ day of hospitalization), showed ESBL-producing Klebsiella pneumoniae and class D carbapenemase.

The esophagogastroduodenoscopy showed esophageal candidiasis, grade 2, ulcerative reflux esophagitis, superficial gastritis and duodenogastric reflux.

The echocardiography (Fig. 3) demonstrated dilatation of the ascending aorta and both atria and signs of the infective endocarditis. The aortic valve leaflets were thickened in the marginal zone, had loose structure due to vegetations, and there were signs of probable perforation of the non-coronary aortic valve leaflet.

For the first ten days, the patient was treated with meropenem $6 \mathrm{~g} /$ day, gentamicin $0.48 \mathrm{~g} /$ day and rifampicin $0.6 \mathrm{~g} /$ day for staphylococcal infection of the skin and soft tissues and bacterial pneumonia, and granulocyte colony-stimulating factor infusions. After the results of laboratory and instrumental investigations, the antibacterial therapy was adjusted: polymyxin B $200 \mathrm{mg} /$ day + tigecycline $100 \mathrm{mg} /$ day $^{+}$ meropenem $6 \mathrm{~g} /$ day. Moreover, antifungal treatment was initiated due to high risk of invasive candidiasis.

Despite the treatment, the patients' state continued to deteriorate, with worsening signs of heart failure, anemia and persistence of Klebsiella pneumonia in blood cultures, and finally exitus.

\section{Discussion}

The well-known manifestations of thymoma are various cytopenic syndromes, for example, partial red cell aplasia ${ }^{19}$. PWCA is a less known hematological complication . In our patient, we assumed a relationship between thymoma and neutropenia. The severity of neutropenia in PWCA can be different, varying from a moderate decrease in the number of neutrophilic granulocytes to agranulocytosis, as in our patient. Neutropenia is referred as a number of neutrophils below $1.0 \times 10^{9} / \mathrm{L}$ in children and $1.5 \times 10^{9} / \mathrm{L}$ in adults, and agranulocytosis (AG) is considered at an absolute number of granulocytes below $500 \times 10^{9} / \mathrm{L}^{20,21}$.

On the background of severe neutropenia, up to $A G$, the patient was diagnosed with sepsis with several primary foci - skin infection with multiple localization, bilateral pneumonia and infective endocarditis (IE). There are two distinct features of the infectious process in this clinical case: first, a rare incidence of IE in patients with AG, and, second, an unusual causative agent for IE, the nosocomial strain Klebsiella pneumoniae producing carbapenemase. IE is considered a rare infectious complication of neutropenia and AG.

Ljungman et al demonstrated that Streptococcus viridans and Staphylococcus spp. are the most common agents of sepsis in patients treated in the hematologic departments. Moreover, there was only one IE case, who met Duke criteria, among 66 documented cases with sepsis ${ }^{22}$. According to other authors, bacteriemia in neutropenic patients receiving cytostatic chemotherapy is usually caused by Streptococcus mitis and Streptococcus sanguis, and IE in these patients is rarely observed $(7-8 \% \text { of cases) })^{23}$.

One of the reasons for the rare development of IE in neutropenic patients is the significant decrease or even loss of production of neutrophilic traps. Neutrophil extracellular traps induce vegetation formation through entrapping bacteria-platelet aggregates on the injured heart valves ${ }^{24}$.

The risk factors for IE in our patient were ischemic heart disease, arrythmias (paroxysms of atrial fibrillation), arterial hypertension, aortic valves alterations (thickening, induration, calcification) and the presence of other infectious foci (pneumonia, pyoderma).

It is worth noting the unusual etiologic agent of IE in our patient. The percentage of infection with Klebsiella pneumonia in neutropenic patients reaches up to $10.8 \%{ }^{25}$, and IE cases have not been described in these patients. In addition, Klebsiella pneumonia is regarded as a rare etiologic agent of IE, and each case of endocarditis of such etiology needs subsequent analysis, especially multidrug-resistant strains being isolated.

In one of the earliest reviews in 1999, Anderson \& Janoff ${ }^{26}$ analysed 48 cases of IE due to Klebsiella pneumoniae, described in the literature. The authors noted that IE extremely rarely complicates bacteriemia with Klebsiella pneumonia. In these cases, the results of antibiotic therapy are unsatisfactory, even in the case 
of sensitive strains, and the mortality rate is about $49 \%$. In another review, the authors also emphasized the rarity of IE cases caused by Klebsiella pneumonia and the high mortality, despite adequate antibiotic therapy, and noted that the early surgical treatment is associated with a better prognosis ${ }^{27}$. Recently, a case of bacteremia with carbapenem-resistant Klebsiella pneumonia and IE was described in a patient after allogeneic bone marrow transplantation, with neutropenia $^{28}$. This patient received a combination of imipenem, sulbactam, gentamycin and tigecycline with a good evolution, being referred to surgery after the correction of AG. There are several cases in the literature with IE caused by Klebsiella pneumonia and Klebsiella oxitoca in intravenous drug addicted ${ }^{29-31}$ and hemodialysis patients ${ }^{32}$. Also, two cases of nosocomial IE in adults and children caused by ESBL-producing Klebsiella pneumoniae have been reported ${ }^{33-34}$.

\section{Conclusions}

We reported a very rare case of IE in a patient with AG, caused by an atypical pathogen, nosocomial highly resistant Klebsiella pneumoniae strain that produces carbapenemase.

This case presents a collection of rarities in one particular patient. The patient was diagnosed with a relatively rare pathology (thymoma) and its equally rare complication, PWCA, with severe neutropenia, complicated by sepsis, with the development of soft tissue infection, pneumonia, and IE caused by a rare agent, carbapenem-resistant Klebsiella pneumoniae.

The rarity of endocarditis caused by Klebsiella species limits its recognition and awareness of its often severe course. Most cases of endocarditis with Klebsiella pneumoniae are associated with prosthetic heart valves. In patients with immunosuppression, such as PWCA associated with thymoma, and endocarditis, rare microorganisms must be considered.

\section{Author Contributions:}

L.I.D., S.V.Y., M.P.S. and A.P.S. were responsible for the diagnostic procedures, clinical diagnosis, and treatment decisions. V.V.V. made the histopathological diagnosis. L.I.D., M.A.K. analyzed the literature and. wrote the manuscript. All authors have read the text and reached an agreement for the manuscript text.

\section{Compliance with Ethics Requirements:}

"The authors declare no conflict of interest regarding this article"

"The authors declare that all the procedures and experiments of this study respect the ethical standards in the Helsinki Declaration of 1975, as revised in 2008(5), as well as the national law. Informed consent was obtained from the patient included in the study"

"No funding for this study"

\section{Acknowledgements:}

None

\section{References}

1. Levitt LJ, Ries CA, Greenberg PL. Pure white-cell aplasia. Antibody-mediated autoimmune inhibition of granulopoiesis. N Engl J Med 1983;308(19):1141-6.

2. Iida S, Noda T, Banno S, Nitta M, Takada K, Yamamoto M. Pure white cell aplasia (PWCA) with an inhibitor against colony-forming unit of granulocyte-macrophage (CFUGM). Rinsho Ketsueki. 1990;31(10):1726-1730.

3. Tamura H, Okamoto M, Yamashita T, et al. Pure white cell aplasia: Report of the first case associated with primary biliary cirrhosis. Int J Hematol. 2007;85(2):97-100.

4. Keast T, Weeraman D, Mayhead P, Grace R, Mathe S. Pure white cell aplasia: Report of first case associated with autoimmune hepatitis. Frontline Gastroenterol. 2014;5(4):287-290.

5. Fumeaux Z, Beris P, Borisch B, et al. Complete remission of pure white cell aplasia associated with thymoma, autoimmune thyroiditis and type 1 diabetes. Eur J Haematol. 2003;70(3):186-189.

6. Marmont AM, Dominietto A, Gualandi F, Piaggio G, van Lint MT, Bacigalupo A. Pure white cell aplasia (PWCA) relapsing after allogeneic BMT and successfully treated with nine DLIs. Biol Blood Marrow Transplant. 2006;12(1):987-9.

7. Ackland SP, Bur ME, Adler SS, Robertson M, Baron JM. White blood cell aplasia associated with thymoma. Am J Clin Pathol. 1988;89(2):260-3.

8. Kobayashi Y, Ando K, Hata T, et al. Complete remission of pure white cell aplasia associated with thymoma after thymectomy and cyclosporine administration. Int $J$ Hematol. 2019;109(3): 346-350.

9. Al Ghazal M, Bu Khamseen R, Al Zaher M, Al Gharyafi M, Alruwaiy Z. WBC aplasia: case report. Hematol Transfus Int J. 2020;8(4):83-84.

10. Alvares CL, Svasti-Salee D, Rowley M, Gordon-Smith EC, Marsh JCW. Remission induced by Campath-1H for thymoma-associated agranulocytosis. Ann Hematol. 2004;83(6):398-400

11. Sato K, Nojiri S, Numata T, et al. Case of agranulocytosis associated with thymoma. Gakkai Zasshi. 2008;46(2):101-5.

12. Lippner EA, Lewis DB, Robinson WH, et al. Paraneoplastic and therapy-related immune complications in thymic malignancies. Curr Treat Options in Oncol. 2019;20(7):62-71

13. Bernard C, Frih H, Pasquet F, et al. Thymoma associated with autoimmune diseases: 85 cases and literature review. Autoimmun Rev. 2016;15(1):82-92.

14. Shelly S, Agmon-Levin N, Altman A, Shoenfeld Y. Thymoma and autoimmunity. Cell Mol Immunol. 2011;8(3):199-202.

15. Tzarfati K, Shiloah E, Koren-Michowitz M, Minha S, Rapoport M. Successful treatment of prolonged agranulocytosis caused by acute parvovirus B19 infection with intravenous immunoglobulins. European Journal of Internal Medicine. 2006;17(6):439-440.

16. Frattini F, Crestani S, Vescovi PP, Franchini M. Pure white cell aplasia induced by mesalazine in a patient with ulcerative colitis. Hematology. 2013;18(3):181-2. 
17. Kalambokis G, Vassou A, Bourantas K, Tsianos EV. Imipenem-cilastatin induced pure white cell aplasia. Scandinavian Journal of Infectious Diseases. 2005;37(8):619620.

18. Sultan S, Irfan SM. Acquired idiopathic pure white cell aplasia: A rare cause of agranulocytosis. J Appl Hematol. 2014;5(4):161-3.

19. Petrenko AA, Pivnik AV, Dudina GA, Dubnitskaya MG. Pure red cell aplasia of the bone marrow in combination with thymoma. A literature review and own data. Ter Arkh. 2019;91(7):121-126.

20. Acquired neutropenias. National Clinical Guidelines. Russian Ministry of Health, 2018. Available at https://www. moph.gov.qa/clinical-guidelines

21. Donadieu J, Fenneteau O, Beaupain B, at al. Congenital neutropenia: diagnosis, molecular bases and patient management. Orphanet Journal of Rare Diseases. 2011; 6(1):2-28.

22. Westling $\mathrm{K}$, Ljungman $\mathrm{P}$, Thalme A, Julander I. Streptococcus viridans septicaemia: a comparison study in patients admitted to the departments of infectious diseases and haematology in a university hospital. Scand J Infect Dis. 2002;34(4):316-31.

23. Bochud PI, Calandra T, Francioli P. Bacteremia due to viridans streptococci in neutropenic patients: a review. Am J Med. 1994;97(3):256-64.

24. Jung CJ, Yeh CY, Hsu RB, Lee CM, Shun CT, Chia JS. Endocarditis pathogen promotes vegetation formation by inducing intravascular neutrophil extracellular traps through activated platelets. Circulation. 2015;131(6): 571-581.

25. Lima SS, França MS, Godoi CC, et al. Neutropenic patients and their infectious complications at a University Hospital. Rev Bras Hematol Hemoter. 2013;35(1):18-22.
26. Anderson MJ, Janoff EN. Klebsiella endocarditis: report of two cases and review. Clin Infect Dis. 1998;26(2):468-74.

27. Brouqui P, Raoult D. Endocarditis due to rare and fastidious bacteria. Clin Microbiol Rev. 2001;14(1):177-207. .

28. Kantarcioglu B, Bekoz HS, Olgun FE, et al. Allogeneic stem cell transplantation in a blast-phase chronic myeloid leukemia patient with carbapenem-resistant Klebsiella pneumoniae tricuspid valve endocarditis: A case report. Mol Clin Oncol. 2016;5(4):347-350.

29. Hauser N, Tanner E, Keuroghlian M, Koduri L. A case of Klebsiella oxytoca endocarditis in an intravenous drug user. ID Cases. 2017;9:77-78.

30. Mohamed A, Hall C, Hatch M, Ayan M, Winn R. Infective endocarditis caused by Klebsiella oxytoca in an intravenous drug user with cancer. Proc (Bayl Univ Med Cent). 2016;29(2):181-2.

31. Riangwiwat T, Dworkin J. Tricuspid valve infective endocarditis due to Klebsiella pneumoniae in intravenous drug user. Hawaii J Med Public Health. 2019;78(3):98-102.

32. Aissaoui H, Hdidou Y, Bougrine R, Ismaili N, Ouafi NE. Infective endocarditis caused by Klebsiella oxytoca in a patient with hemodialysis: a CARE-compliant case report and review of the literature. J Saudi Heart Assoc. 2020;32(2):307-310.

33. Shipton SE, Cotton MF, Wessels G, Wasserman E. Nosocomial endocarditis due to extended-spectrum beta-lactamase-producing Klebsiella pneumoniae in a child. S Afr Med J. 2001;91(4):321-2.

34. del Arco A, Olalla J, De la Torre J, García-Alegría J. Endocarditis caused by extended spectrum beta lactamase producing Klebsiella. Rev Clin Esp. 2011;211(3):163-4. 